\title{
A BRINCADEIRA DE FAZ DE CONTA DE PAPÉIS SOCIAIS: UMA REELABORAÇÃO CRIATIVA DA CRIANÇA SOBRE AS RELAÇÕES DE TRABALHO
}

\author{
MAKE-BELIEVE ACTIVITIES: \\ A CREATIVE RE-ELABORATION OF THE CHILD REGARDING WORK RELATIONSHIPS
}

\author{
EL JUEGO DE LOS PERSONAJES SOCIALES: \\ UNA REVELACIÓN CREATIVA DEL NIÑO SOBRE LAS RELACIONES LABORALES
}

Géssica de Aguiar Lima

Mestra em Educação

Universidade Federal do Oeste do Pará - UFOPA

Pará - Brasil

gessica.ufpa@gmail.com

Sinara Almeida da Costa

Doutora em Educação

Universidade Federal do Oeste do Pará - UFOPA

Pará - Brasil

sinaraacs@hotmail.com

\begin{abstract}
Resumo: Este estudo almeja compreender de que forma as crianças ressignificam, por meio da brincadeira de faz de conta, situações sociais de argumento do trabalho vivenciadas por elas no processo de desenvolvimento da personalidade e, especificamente, identificar as funções psíquicas superiores envolvidas nessa atividade, bem como destacar o papel da professora nesse processo. Provém de uma pesquisa de mestrado que buscou compreender de que forma a brincadeira de faz de conta de papéis sociais contribui no desenvolvimento da personalidade das crianças, segundo os pressupostos da Teoria Histórico Cultural. De cunho experimental, os dados da pesquisa foram produzidos em uma Unidade Municipal de Educação Infantil (UMEI) do município de Santarém, PA, por meio de observações da rotina das crianças e de dupla intervenção: inserção de brinquedos no contexto educativo e formação continuada junto à professora participante da pesquisa sobre a brincadeira de faz de conta de papéis sociais. Os dados foram registrados em vídeos, fotografias e diário de campo. Os resultados revelam que a brincadeira de faz de conta de papéis sociais possibilita efeitos educativos que exercem influência sobre o desenvolvimento da personalidade das crianças que, ao brincarem, representam as regras, conteúdos e temas advindos das relações sociais. As crianças representaram, no faz de conta, dentre outros aspectos, papéis sociais de argumento do trabalho, expressando como percebem as relações de poder do sistema capitalista de produção.
\end{abstract}

Palavras-chave: Brincadeira de faz de conta. Educação infantil. Trabalho.

Abstract: This study aims to understand the way children resignify social situations experienced for themselves through make-believe activities, regarding work relationships, experienced by them in the process of personality development, and specifically identify superior psychological functions involved in make-believe activities, as well how to highlight the role of the teacher in this process. It comes from a master's research that sought to understand how make-believe activities contributes to the development of the children's personality, according to the assumptions of the Cultural Historical Theory. The research data were produced in a Municipal Infant Education Unit (UMEI) in the city of Santarem, PA, through observations of the routine of children and double intervention: insertion of toys in the educational context and continuing education with professor who participates in the research on social role make-believe. The data were recorded in videos, photographs and field diary. The results show that make-believe activities possible educational effects that influence the development of the personality of the children who, in playing, represent the rules, contents and themes arising from social relations. The children represented in the face of, among other aspects, social roles of work argument, expressing how they perceive the power relations of the capitalist system of production.

Keywords: Make-believe activities. Infantile education. Work.

Resumen: Este estudio tiene como objetivo comprender cómo los niños resignifican, a través del juego de los personajes sociales, situaciones sociales de trabajo vividas por ellos en el proceso de desarrollo de la personalidad y, específicamente, identificar las funciones psíquicas superiores involucradas en esta actividad, así como destacar el rol docente en este proceso. Surge de una investigación de maestría que buscó comprender cómo el juego de los personajes sociales contribuye al desarrollo de la personalidad de los niños, según los supuestos de la Teoría Histórica Cultural. De naturaleza experimental, los datos de la investigación fueron producidos en una Unidad Municipal de Educación Infantil (UMEI) en el municipio de Santarém, PA, a través de observaciones de la rutina infantil y doble intervención: inserción de juguetes en el contexto educativo y formación continua con el docente participante en el investigación sobre el juego de los personajes sociales. Los datos se registraron en videos, fotografías y un diario de campo. Los resultados revelan que el juego permite efectos educativos que influyen en el desarrollo de la personalidad de los niños que, al jugar, representan las reglas, contenidos y temas que surgen de las relaciones sociales. Los niños representados ante, entre otros aspectos, los roles sociales del argumento del trabajo, expresando cómo perciben las relaciones de poder del sistema capitalista de producción.

Palabras clave: Juego de los personajes sociales. Educación Infantil. Trabajo.

Para citar - (ABNT NBR 6023:2018)

LIMA, Géssica de Aguiar; COSTA, Sinara Almeida da. A brincadeira de faz de conta de papéis sociais: uma reelaboração criativa da criança sobre as relações de trabalho. Eccos - Revista Científica, São Paulo, n. 56, p. 1-15, e13460, jan./mar. 2021. Disponível em: https://doi.org/10.5585/eccos.n56.13460. 


\section{Introdução}

No processo de humanização, a escola da infância tem o importante papel de criar possibilidades de vivências positivas ao desenvolvimento da personalidade das crianças. E a brincadeira de faz de conta pode ser o fio condutor dessas vivências, pois, por meio dessa atividade, a criança pode exercer sua liberdade, expressar suas ideias, fazer escolhas, e, principalmente, representar situações além do seu nível de desenvolvimento real, por meio da imaginação. Oportunizando isso às crianças, a escola, além de garantir seus direitos (brincar, interagir, expressar-se), pode vislumbrar as necessidades de desenvolvimento infantil como, por exemplo, em que aspectos pode intervir na formação social dos indivíduos.

A brincadeira de faz de conta de papéis sociais possibilita efeitos educativos que exercem influência sobre o desenvolvimento da personalidade das crianças, inculca independência, educa no amor ao trabalho e pode corrigir desvios comportamentais, ajuda a formar uma coletividade ou sociedade infantil ajustada, ou seja, no faz de conta, a criança passa a perceber as atividades humanas, as normas de conduta social e desenvolve-se moralmente. É, também, uma atividade com níveis de desenvolvimento e permite a transição para um novo período de desenvolvimento do processo de humanização (ELKONIN, 2009).

Inspirando-se nas ideias de Vigotski (2000, 2000a, 2008, 2009, 2010, 2010a) e seus seguidores, como Elkonin (2009), este estudo de cunho explicativo propôs-se a compreender de que forma as crianças ressignificam, por meio da brincadeira de faz de conta, situações sociais de argumento do trabalho vivenciadas por elas e, especificamente, identificar as funções psíquicas superiores envolvidas nessa atividade, como, também, destacar o papel da professora nesse processo. Caracteriza-se como estudo experimental, realizado em uma Unidade Municipal de Educação Infantil (UMEI) de Santarém, PA.

Seguindo os princípios metodológicas de Vigotski (2000a, 2010), provenientes do materialismo histórico-dialético, que considera as contradições, o movimento e as permanentes transformações no meio social como a própria lógica de ser e estar no mundo, exigindo dos sujeitos que dele fazem parte a capacidade de dinamizar a relação que há entre a emancipação e alienação, conforme as possibilidades que lhes são apresentadas, buscou-se compreender e intervir na realidade estudada no intuito de explicar os fenômenos implícitos em cada situação de brincadeira de faz de conta de papéis sociais cujo argumento evidenciasse as relações de trabalho.

Para tanto, foi realizada dupla intervenção no contexto da pesquisa: inserção de brinquedos e formação continuada com a professora participante do estudo, em busca de criar 
melhores possibilidades de efetivas situações sociais de desenvolvimento envolvendo a brincadeira de faz de conta.

A inserção dos brinquedos criou uma situação laboratorial por "colocar a criança em condições especiais" (VIGOTSKI, 2010, p. 439) para atingir os objetivos da pesquisa. Neste caso, as crianças desfrutaram de mais brinquedos e livros, mais espaço e tempo para o brincar livre. Dentre as vantagens dos estudos experimentais laboratoriais, destaca-se a capacidade de possibilitarem mudanças no comportamento das pessoas investigadas.

A formação continuada, por sua vez, possibilitou à docente rever suas ideias sobre a brincadeira, contribuindo para que passasse a reconhecê-la e valorizá-la como atividade desenvolvente das crianças pré-escolares. Constatou-se, por meio de observações participantes, que a brincadeira passou a ocupar um lugar de destaque nas ações pedagógicas, desde o planejamento à avaliação, o que contribuiu diretamente no desenvolvimento dessa pesquisa.

As representações criativamente elaboradas pelas crianças da pesquisa formam um conjunto de vivências, compartilhadas na sociedade infantil escolar e, também, são frutos das intervenções da professora no conteúdo da brincadeira de faz de conta. Dessa forma, os papéis assumidos por elas, as regras, conteúdos e temas das brincadeiras, evidenciaram o faz de conta de papéis sociais como uma forma tipicamente infantil de representar criativamente o que se internaliza do meio social, viabilizando o reconhecimento dessa atividade como um elemento indispensável ao processo de humanização.

Portanto, na brincadeira de faz de conta de papéis sociais, a realidade da criança é criativamente representada por ela, seus modos de vida, a operação com os objetos, a particularidade e a universalidade da cultura e, especialmente, aquilo que é fundamental ao desenvolvimento da personalidade: as relações entre as pessoas.

\section{As relações de trabalho a partir do olhar brincante infantil}

A seguir, apresenta-se alguns conceitos sobre a brincadeira de faz de conta de papéis sociais (argumento, papeis, níveis de desenvolvimento etc.) e expõe-se episódios em que as crianças expressam suas ressignificações sobre as relações de trabalho. Os dados, em geral, revelam que as representações dessas relações, espelhadas na sociedade capitalista de produção, são permeadas pela competitividade, submissão, lucro, conformismo, mas, também, por atitudes de cooperação, partilha, liderança, autoafirmação, cuidado, empatia e coragem. 


\subsection{Os papéis e os argumentos da brincadeira de faz de conta-alguns conceitos}

Para Elkonin (2009), no brincar das crianças pré-escolares existem duas características fundamentais, os papéis e os argumentos. Estes servem de termômetro para verificar o desenvolvimento das crianças. Mas, para isso, deve-se levar em consideração as condições objetivas da vida de cada uma. Ainda para o autor, os papéis assumidos e o argumento do brincar tendem a se desenvolver de forma que a criança consiga, ao interpretar os papéis, perceber o outro e suas peculiaridades, diferenciando-o ou associando-o a si.

Com a evolução dessa percepção, o argumento da brincadeira, ou seja, a obediência à realização de determinadas ações para representar um papel, tem mais rigor. As regras sociais se fazem mais explícitas. A criança começa a diferenciar o que é de si e o que é do outro nessa representação. Assim,

\footnotetext{
Surgem regras internas não escritas, mas obrigatórias, provenientes do papel e da situação lúdica. Quanto mais desenvolvido está o jogo, tanto maior é o número de regras internas e os aspectos lúdicos multiplicam-se e ampliam-se cada vez mais, envolvendo as inter-relações histriônicas ${ }^{1}$ das crianças, os sentidos atribuídos aos brinquedos e a continuidade do desenvolvimento do argumento (ELKONIN, 2009, p. 243).
}

O faz de conta, portanto, possibilita situações de ensino-aprendizagem que desenvolvem novas necessidades na criança, tais como: a percepção de si, o desenvolvimento do pensamento abstrato e o ato de seguir regras internas, provenientes do meio externo (controle da vontade) para desempenhar melhor um papel. Dessa maneira, no desenvolvimento dessas qualidades humanas, a relação com o outro é essencial para que, nas próximas etapas do desenvolvimento, a criança atue como ser crítico, com autonomia e respeito (não submissão) às regras culturalmente estabelecidas, percebendo a si, ao outro e os diferentes papéis sociais.

Para Elkonin (2009), a essência da brincadeira consiste nas relações sociais, e seu desenvolvimento possui fases relacionadas aos tipos de interações que as crianças estabelecem com os objetos e pessoas. Esses tipos podem ser agrupados em duas fases fundamentais: a primeira ( 3 a 5 anos) corresponde ao primeiro e segundo níveis, os quais têm em comum o conteúdo: ações objetais, de orientação social; e a segunda (5 a 7 anos) corresponde ao terceiro e quarto níveis, nos quais o conteúdo da brincadeira reflete as relações sociais reais estabelecidas entre as pessoas e o sentido social de sua atividade.

Esses níveis de desenvolvimento propostos por Elkonin (2009) podem ou não ocorrer nas respectivas etapas, a depender das relações estabelecidas no meio social e das motivações

\footnotetext{
${ }^{1}$ Refere-se à atuação teatral ou dramática da criança ao assumir um papel social.
} 
geradas no interior da criança para atingir o nível da representação criativa das relações humanas. O conteúdo da brincadeira pode se desenvolver das relações objetais às relações sociais antes dos cinco anos, assim como pode tardar. As experiências vivenciadas pelas crianças são condicionantes desse desenvolvimento.

Os episódios apresentados adiante têm como referências as diferentes formas de manifestação da atividade guia do adulto - o trabalho - na brincadeira de faz de conta de papéis sociais. Segundo Elkonin (2009), o desenvolvimento desse tipo de argumento expande o conhecimento das crianças acerca das relações que estabelecem no meio, tendo em vista que há predominância de conteúdo do contexto familiar nas brincadeiras de faz de conta, o que manifesta a importância de as crianças conhecerem outros tipos de relações sociais.

Isolada no meio da família e das relações familiares, e vivendo em seu quarto infantil, a criança, como é natural, reflete principalmente nos jogos essas relações e as funções que os membros da família exercem com ela e entre eles. Talvez provenha daí a impressão de que existe um mundo infantil especial de jogo como atividade cujo conteúdo fundamental são as formas compensatórias de toda a natureza que refletem a tendência da criança para escapar desse ambiente fechado ao mundo das vastas relações sociais (ELKONIN, 2009, p. 398).

Esse teórico complementa que, quando a criança assume algum papel social do adulto, como: motorista, médico, marinheiro, capitão, vendedor, ela não adquire seus hábitos, tais como dirigir, pilotar, manejar uma seringa. O que há, portanto, é a percepção do uso social dos objetos. Assim, na brincadeira em sua forma mais desenvolvida, mais importante que atuar com os objetos é o plano das relações que cada um desses papéis estabelece com os outros parceiros ao brincar, de modo que consiga comparar a conduta do papel assumido à sua conduta real, o que Elkonin (2009, p. 417) denomina de conduta arbitrada, fator importante ao desenvolvimento da personalidade.

\subsection{As ressignificações criativas das crianças sobre as relações sociais de trabalho}

As brincadeiras destacadas nos episódios a seguir evidenciaram as ressignificações que as crianças fizeram das relações sociais que vivenciam no meio, bem como os processos psicológicos em desenvolvimento nelas (fala, imaginação, função simbólica da consciência, controle da vontade, escrita). Dentre as ressignificações feitas por elas, foram destacadas as representações de papéis sociais de argumento do trabalho elaboradas na sociedade infantil escolar e enriquecidas mediante às intervenções da professora (planejamento, organização do espaço e tempo, observações com questionamentos e reflexões ocasionais). 
São analisados dois dos quarenta e oito episódios sobre esse argumento registrados na pesquisa, os quais foram selecionados por apresentarem maior nível de desenvolvimento do brincar, conforme Elkonin (2009).

\section{Episódio 1: O supermercado}

Participantes: Crianças, professora e pesquisadora

Ação mediadora da professora: A professora organizou um ambiente sugestivo no quintal, referente ao supermercado que havia visitado com as crianças no dia anterior. Pôs prateleiras, embalagens e caixas de alimentos, uma caixa registradora, carrinhos de compras, papéis similares a dinheiro e cartões de crédito. Deixou que as crianças interagissem livremente no local enquanto as observava. Interviu na brincadeira quando percebeu a necessidade do compartilhamento das sacolas entre as crianças.

\section{Conteúdo da brincadeira de faz de conta (ações, operações com objetos e} interações entre os participantes):

As crianças distribuíram os papéis e começaram a brincar de supermercado. Enquanto Saraipora brincava de caixa de supermercado, Muiraquitã pagava sua conta.

- É dinheiro a folha. - Laurimar constatou, dirigindo-se à pesquisadora.

- "Tá" bom. - ela disse compreendendo o significado que ele atribuiu ao elemento da natureza.

Ao lado, Icamiaba estava atrás das prateleiras de produtos. Vitória Régia, na parte da frente, disse:

- A minha filha está "dodói". - pegando um produto da prateleira.

- Tem remédio para ela. Esse aqui é o remédio dela, né? Olha. As "sereias" é o remédio dela. - Icamiaba disse, entregando uma caixa para sua cliente que foi até Saraipora pagar a conta.

Logo depois, Laurimar disse:

- Olha o que eu achei aqui! - mostrando um cartão.

Ele foi até Saraipora e ficou aguardando para ser atendido, já que Vitória Régia ainda estava pagando suas compras. Vitória Régia avisou a caixa:

- Eu tenho cartão.

Saraipora recebeu e passou o cartão.

A pesquisadora orientou:

- Não esquece de digitar o número. Dirigindo-se à Vitória Régia, pois percebeu que Saraipora queria executar todas as ações possíveis com o cartão.

Vitória Régia não se importou com a solicitação da pesquisadora e pegou suas compras que estavam no chão, nas cestas de compras.

Ao ver Manioca passar ao lado com uma sacola nas mãos, Vitória pediu, mas Manioca se negou a dar.

- Olha, aqui estão os sacos para colocar as coisas que vocês comprarem. Ela é a vendedora (Icamiaba), mas tem que pagar no caixa. - a professora interviu ao perceber que algumas crianças estavam dando o dinheiro a quem estava atrás da prateleira.

As crianças ficaram eufóricas para pegar as sacolas. Então, a professora disse:

- A Manioca tem mais sacolas.

Algumas crianças compravam com Icamiaba e pagavam com Saraipora. Manioca era a vendedora da feirinha do supermercado, por isso havia retido as sacolas.

A pesquisadora percebeu que Tucandeira não queria ser cliente e sim vendedora. Então solicitou:

- Icamiaba deixa a Tucandeira vender um pouquinho, depois você volta.

A menina ficou parada, não respondeu nada e continuou a receber os pagamentos atrás da prateleira, sem direcionar as crianças ao caixa.

No momento, Guaraná estava na vez de pagar. Ele foi até Saraipora, com um saco de compras na mão e a cutucou. Ela, por sua vez, passou um cartão na máquina e disse:

- Seu cartão, paguei. - entregando-o a ele.

Guaraná recebeu o cartão e foi embora.

Enquanto isso, Wilson Fonseca reivindicava ser o vendedor. A professora então direcionou:

- Tem que pedir para o gerente te contratar. Quem é o gerente? 


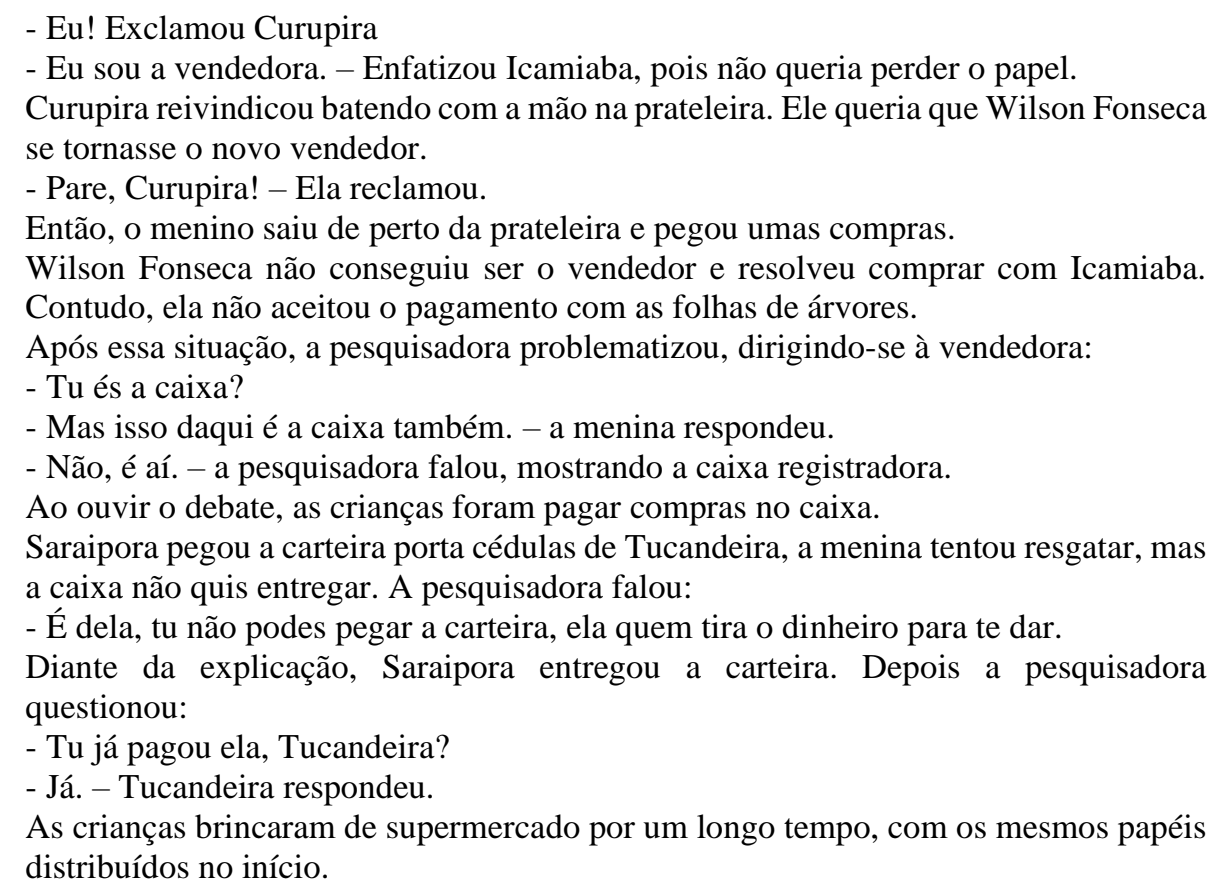

As ações lúdicas imaginárias reproduzem conteúdo do trabalho pertinentes às relações sociais de compra e venda. Mais de três crianças desenvolveram o argumento do tema sob o olhar observador da professora e da pesquisadora. Os papéis do episódio foram determinados pelas crianças e distribuídos entre os parceiros da brincadeira, conforme a interação que tiveram com os objetos no ambiente sugestivo: o domínio da caixa registradora tornou a criança o caixa; quem pegou o carrinho e cestas pôs-se a comprar os objetos; e quem se posicionou atrás das prateleiras tornou-se vendedora. Houve também a tentativa, por parte de algumas crianças, de experimentarem diferentes papéis, contudo enfrentaram resistência daquelas que já os haviam assumido.

Ainda que as ações e papéis assumidos pelas crianças tenham sido incitados pelos objetos dispostos no espaço organizado pela professora, os envolvidos na brincadeira não condensaram suas ações na representação do que o objeto propõe. Os significados desses objetos possibilitaram que as crianças interagissem ludicamente umas com as outras, de modo que suas ações apresentaram certo grau de lógica, articulando as relações dos parceiros da brincadeira ao que acontece nas relações reais.

Contudo, destacam-se alguns trechos em que crianças demonstraram dificuldade em respeitar a sequência lógica das ações em relação àquelas articuladas com seus companheiros: Icamiaba, a vendedora, além de entregar os objetos dispostos nas prateleiras, recebia o dinheiro quando algumas crianças lhe ofereciam, executava, portanto, a função da colega que estava no caixa. Do mesmo modo agia Saraipora no caixa quando tomava a carteira do cliente para retirar 
o cartão e, ela mesma, digitava a senha pagando a conta. Tais acontecimentos interferiram na atuação da professora e da pesquisadora que interviram no brincar das crianças diversas vezes em busca de organizar a sequência lógica de suas ações. Apesar dessa intenção, está implícita nas intervenções a necessidade que ambas tinham de controlar os acontecimentos da brincadeira, de enfatizar as regras sociais e direcionar a atuação das crianças. Trata-se de uma atitude que exige cuidado, pois, ao invés de criar condições para que a brincadeira se desenvolva a um nível mais elevado, o que envolve a lógica das ações (ELKONIN, 2009), corre-se o risco de destruir a liberdade da brincadeira de faz de conta (KISHIMOTO, 2000).

A organização do espaço e a relação das crianças com ele mostraram que há a reprodução, na brincadeira de papéis sociais, das experiências proporcionadas pela escola às crianças, como forma de ampliar os temas do brincar. Contudo, as ações representadas criativamente por elas tomam como base um complexo de experiências do contexto do qual participam. Diante disso, ao analisar a conduta de Saraipora, que, além de vender os produtos, recebia o dinheiro, não se pode refletir, somente, pela perspectiva das relações de trabalho dos grandes supermercados, como o visitado por ela junto à professora. É importante discutir que, no contexto santareno, nos pequenos comércios ("taberna", mercantil, mini-box), o papel assumido por Saraipora exerce diversas funções: vende, troca a mercadoria, recebe os pagamentos, reabastece o estabelecimento, pesa os produtos, o que não foi percebido no momento da intervenção da pesquisadora. Então, negar a lógica das ações de Saraipora pode se configurar em equívoco, sob essa perspectiva.

Por outro lado, o diálogo entre Vitória Régia (cliente) e Saraipora (vendedora de remédios) sobre o que dar para a filha doente, bem como a fila para o pagamento das compras, demonstram a existência de um sentido social da representação criativa das crianças. Pôr-se a esperar na fila de pagamento, ter dinheiro para poder levar as compras são regras da sociedade capitalista a qual as crianças pertencem. Essas características evidenciam que as crianças, em sua maioria, transitaram, no episódio, pelo terceiro nível de desenvolvimento do brincar (ELKONIN, 2009).

Devido não possuir a verba para pagar as compras, no início do episódio, Laurimar substitui o uso do "dinheiro", disponibilizado pela professora, pelas folhas de árvore que havia encontrado no chão, o que evidencia o desenvolvimento da função simbólica da consciência, em que "o uso de objetos para substituir objetos ausentes e necessários a interpretação do papel exige a separação entre o campo real (ótico) e o campo do significado (imaginário)" (MARCOLINO, 2017, p. 156). Apesar de a folha ter as "exigências mínimas de semelhança do 
objeto substitutivo com o representado" (ELKONIN, 2009, p. 225): espessura e cor, por exemplo, essa substituição não foi aceita por Icamiaba, que se negou a receber o pagamento de Wilson Fonseca, deixando-o entristecido. Elkonin (2009) exemplifica o porquê disso ocorrer:

Todos os objetos inseridos no jogo e dotados de um certo sentido do ponto de vista do papel devem ser aceitos nesses precisos sentidos por todos os participantes do jogo, embora não atuem realmente com eles. Assim, por exemplo, no jogo de "médico" [...], há forçosamente duas crianças para jogar, o médico e o paciente. O médico deve coordenar seus atos com o papel do paciente e vice-versa. Isso se refere também aos objetos. Imaginemos que o médico tem nas mãos um pauzinho que faz as vezes de uma seringa. E é seringa para ele porque a aciona de certa maneira. Mas para o paciente não deixa de ser um pedaço de pau. (p. 412).

Partindo dessa concepção, Elkonin (2009, p. 412) percebe a brincadeira de faz de conta de papéis sociais como "atividade cooperante das crianças", em que os significados atribuídos aos objetos precisam ser compartilhados por todos, num processo de "descentramento" permanente, em que, nas relações entre os companheiros do brincar, as crianças podem coordenar seus pontos de vista e dialogar sobre as ideias adotadas no enredo desenvolvido.

Outras funções psíquicas superiores a se destacar são: a fala, nas relações histriônicas, o controle da vontade, na fila organizada, e a imaginação.

De modo geral, as relações de trabalho apresentadas neste e nos episódios subsequentes retratam sobre capital, competitividade e lucro. A esse respeito, nesse episódio, pontuam-se duas oportunidades de intervenção frente ao modelo de relação capitalista. Ambas constituemse em possibilidades de contribuição na formação da personalidade de pessoas cooperativas e empáticas.

Na primeira, as crianças externalizaram que têm dificuldades de sair da posição que assumem, em referência aos papéis principais. Coincidentemente ao que é visto no capitalismo, esses papéis representaram os detentores do negócio comercial, os que recebem o dinheiro, os que lucram. Destaca-se, todavia, que, no episódio, não havia um dono do supermercado explicitamente determinado, o que permite considerar que, hierarquicamente, os papéis do vendedor e do caixa ocuparam os melhores cargos da brincadeira.

Quanto aos clientes, apesar da tentativa de assumir outro papel, em sua maioria, conformaram-se diante da resistência dos colegas e seguiram reproduzindo o que o tema lhes exigia, com exceção de Curupira, que reivindicou confrontando Icamiaba, na tentativa de dar o lugar de vendedor a Wilson Fonseca. A atitude de Curupira, geralmente, é comum aos préescolares maiores, que demonstram "uma autêntica preocupação pelas pessoas de quem gostam 
e dirigem seus atos no sentido de preservar essas pessoas da intranquilidade ou dos desgostos" (MUKHINA, 1995, p. 214).

Desse modo, a primeira forma de intervenção no conteúdo da brincadeira foi o incentivo - na forma de proposta, não imposição - à troca de papéis, depois de algum tempo decorrido do início do tema, na tentativa de atender os interesses das crianças, para que pudessem representar aquilo que muitas vezes foge do seu campo de relações imediatas. Acredita-se que essa motivação, apesar de não ter sido atendida pelas crianças, pode desencadear tanto a luta pela ascensão dos que não conseguiram o que desejavam, como também a empatia nos que se negaram a perder o papel que ocupavam.

Quanto à segunda intervenção feita pela professora, ao motivar o compartilhamento das sacolas que estavam em posse de Manioca, diante da necessidade do grupo brincante, houve a possibilidade do desenvolvimento de atitudes colaborativas, da atenção às necessidades dos outros e da descentralização dos interesses particulares em prol da coletividade.

Tais problematizações elucidam a importância da intervenção do professor no conteúdo da brincadeira. Os efeitos da intervenção podem não se manifestar imediatamente nas ações das crianças, pela necessidade que têm de realizar seus desejos na brincadeira, mas indicam um modo de relação social que precisa ser mais explorado no contexto educativo, a colaboração. Contraditoriamente, a autoafirmação, a luta pelo que se deseja, também precisam ser instigadas.

Episódio 2: Pronto socorro

Participantes: Crianças, professora e pesquisadora

Ação mediadora da professora: A professora organizou um ambiente sugestivo na sala de atividades, referente ao posto de saúde que havia visitado com as crianças no dia anterior. Pôs colchonetes como se fossem macas, giz de cera ao lado de um bloco de anotação, caixas de remédios e brinquedos: estetoscópios, máscaras, toucas, termômetros etc. Deixou que as crianças interagissem livremente no local enquanto as observava. Interviu no enredo problematizando o uso da maca pelas crianças que carregavam os pacientes.

Conteúdo da brincadeira de faz de conta (ações, operações com objetos e interações entre os participantes):

No hospital, Tucandeira estava na maca, enquanto Jaci lhe examinava. Ele pegou uma injeção e disse:

- Abre a boca. - e colocou a injeção na boca da paciente.

Depois fingiu cortar o cabelo dela. Enquanto isso, Vitória Régia mostrou um papel para Manioca e disse:

- Olha aqui, doutora! Já foi a Tucandeira e já foi a Iara, falta a outra.

- Já podes levantar, paciente! - a professora orientou.

- Já pode levantar. - Jaci enfatizou.

Vitória Régia continuou organizando as "fichas" dos pacientes:

- O Boitatá já foi... - e riscou o papel.

A pesquisadora falou:

- O Boitatá já foi.

- Não, não foi não. - A menina lhe corrigiu.

Ela foi até a maca, olhou que o menino estava deitado lá e riscou o papel.

- O Boitatá já foi agora? 
- Já.

- Ah tá!

- Quem já foi, Vitória?

- Já foi ele.

- Quem mais já passou aí pelo médico?

- Ele é o último.

- Quem já participou da consulta hoje? A pesquisadora insistiu no intuito de saber se a menina recordava o que estava na lista que indicou no princípio.

- Só a Tucandeira. Ela afirmou, esquecendo-se de Iara.

Guaraci foi até Vitória e falou que havia um novo paciente. Curupira estava deitado no chão. A pesquisadora questionou:

- O que aconteceu?

Ninguém respondeu, pois estavam socorrendo o menino. Jaci seguiu verificando os batimentos cardíacos e Guaraci cortando as roupas do paciente.

Curupira ficou se debatendo no chão e motivou algumas crianças a executarem a mesma ação. Umas deitaram-se no chão simulando um acidente de trânsito, outras fizeram o papel de médico atendendo aos acidentados.

Jaci colocou um colchonete no chão, que para ele era uma maca e se pôs a socorrer, mas numa mesma maca deitaram Tucandeira e Boitatá. O então médico pediu que Tucandeira saísse da maca para que ele e Uirapurú carregassem somente Boitatá, mas a menina não atendeu ao pedido. A pesquisadora solicitou:

- Tucandeira, deixa ele (Jaci) carregar ele (Boitatá), Tucandeira.

Jaci tentou levantar os dois do chão, mas não conseguiu, e falou:

- Me ajuda aqui, Uirapurú.

Uirapurú o ajudou, porém não tiveram êxito. Jaci pediu mais uma vez para que Tucandeira levantasse e mais uma vez ela não levantou. A pesquisadora sugeriu:

- Ei, Tucandeira, deixa ele levar de um por um, depois ele vem te buscar.

Tucandeira deitou fora da maca, Jaci e Norato tentaram levantar Boitatá.

Temendo que alguém se machucasse, a professora sugeriu:

- É melhor colocar a boneca na maca!

- É! - a pesquisadora concordou.

- Carrega! Carrega esse! - Jaci motivou. Iara abraçou a maca pelo meio e também ajudou a levantar o menino, mas eles conseguiram levantá-lo por pouco tempo e logo colocaram-no de volta no chão. A pesquisadora alertou:

- Vocês vão machucar mais o doente! Eu acho que a boneca é mais leve mesmo.

As crianças ainda tentaram mais uma vez e, em seguida, desistiram.

Tucandeira colocou uma boneca no lugar de Boitatá e a levaram na maca para o "hospital". Ao constatar que Muiraquitã estava ocupando a maca do hospital, a pesquisadora falou:

- Crianças primeiro. Muiraquitã dá licença, vai chegar um bebê. O atendimento à boneca não foi feito porque os médicos estavam socorrendo as demais crianças deitadas no chão. Tucandeira também não permitiu o atendimento, tomou a boneca nos braços e pôs-se a brincar.

Enquanto isso, Vitória Régia foi até a pesquisadora e disse:

- Eu vou para casa, porque eu tenho uma filha. - encerrando o seu expediente no hospital.

- Tá bom. - a pesquisadora concordou.

Muitas crianças continuavam deitadas no chão. A pesquisadora disse:

- Gente, têm poucos médicos cuidando dessas pessoas.

Iara e Jaci continuaram tentando carregar os acidentados, mas não conseguiram carregá-los por longas distâncias. Jaci se cansou e deitou-se na maca. A pesquisadora falou:

- Até o médico já está ficando doente. - e sorriu.

Iara, Uirapurú, Boitatá e Wilson Fonseca tentaram levar Jaci na maca para o hospital. O cansaço do médico modificou os papéis envolvidos na brincadeira que se reconfigurou. 
O episódio analisado possui papéis determinados e assumidos pelas crianças antes do início da brincadeira: médicos, enfermeiros, secretária e pacientes; as ações lúdicas imaginárias das crianças seguem um enredo construído coletivamente; houve a reelaboração de situações sociais vivenciadas pelas crianças, dentre elas, as condizentes ao enriquecimento do conteúdo da brincadeira de faz de conta de papéis sociais: visita ao posto de saúde, além dos objetos e ambiente sugestivos para que ela acontecesse; houve intervenções (falas: questionamentos, sugestões) por parte da professora e pesquisadora durante o brincar das crianças; houve a participação de um significativo número de crianças. Nesse episódio, portanto, estão evidenciadas características do terceiro nível de desenvolvimento do brincar (ELKONIN, 2009).

As funções psíquicas superiores percebidas no episódio analisado são: a imaginação, na representação criativa dos papéis sociais, envolvendo o argumento do trabalho desenvolvido em um hospital; a fala, nas relações histriônicas entre os participantes, desde a organização dos papéis (relações reais ${ }^{2}$ ) às falas expressadas na situação lúdica imaginária; o controle da vontade, quando Tucandeira aceitou descer da maca, após inúmeros argumentos; a função simbólica da consciência, pela utilização substitutiva de objetos: colchonete-maca; a escrita, como "forma indissolúvel de domínio do meio externo cultural e do pensamento", neste caso, diretamente relacionada ao desenvolvimento da memória voluntária (VIGOTSKI, 2000, p. 29), quando Vitória Régia escreve, da sua maneira, a ordem dos atendimentos médicos.

Sobre esse último aspecto, percebe-se a escrita como uma função psíquica superior ainda não internalizada pela criança, tendo em vista sua complexidade de signos linguísticos. Ela apresenta-se, portanto, em um processo inicial de internalização (garatujas) e necessita de uma série de instruções - na alfabetização - para que se desenvolva até a forma ideal culturalmente estabelecida. Todavia, pode ser observada, no episódio, a percepção da possível função social da escrita, como um modo de lembrar o que se passa, o que se pensa, uma extensão da memória.

As crianças expressaram as significações que têm internalizado das relações sociais no trabalho hospitalar, em que os conteúdos: cuidado, morte, acidente, doenças, formaram o enredo da situação lúdica imaginária. Também, o enredo elaborado atraiu outras crianças para a brincadeira, que expressaram dramaticamente o sofrimento.

\footnotetext{
${ }^{2}$ Surgem em torno da brincadeira, nas discussões sobre seu conteúdo, na discussão dos papéis etc., a criança aprende a respeitar realmente os interesses do companheiro e a cooperar no empreendimento comum. (MUKHINA, 1995).
} 
No episódio registrado, a colaboração esteve fortemente evidenciada. A situação representada exigia dos companheiros da brincadeira atenção, compromisso e cuidado na tentativa de socorro aos pacientes, em ações articuladas dos médicos para com os possíveis enfermeiros.

Dessa forma, as relações sociais em processo de internalização pelas crianças, em relação aos papéis assumidos no tema, sinalizam que, para elas, um médico precisa ser atencioso, trabalhar em colaboração com outros profissionais ter uma agenda de atendimentos organizada e estar atento às emergências; um paciente expressa sofrimento, fraqueza e requer cuidados imediatos; um enfermeiro acompanha o médico em suas ações; a secretária, além de ajudar na organização dos atendimentos, tem uma vida fora do hospital: “-Eu vou para casa, porque eu tenho uma filha.", uma responsabilidade que transcende o contexto do trabalho.

Assim, elas compuseram, coletivamente, um enredo enriquecido com papéis e ações sociais articuladas umas com as outras. Dessa forma, tiveram uma série de modelos para comparar sua conduta, para refletir sobre si mesmas por meio do outro. Segundo Mukhina (1995), na pré-escola, a criança desenvolve sua autoconsciência, "compreende o que representa, que qualidades tem, como se comportam para com ela os que a rodeiam e a que se deve esse comportamento. A autoconsciência manifesta-se sobretudo no auto avaliação" (p. 207). Assim, para que a criança compreenda a si mesma, precisa "primeiro aprender a julgar aos demais, que pode observar de fora" (p. 207).

A esse respeito, Elkonin (2009) comenta:

Há fundamento para supor que, ao representar um papel, o modelo de conduta implícito nesse papel, com o qual a criança compara e verifica a sua conduta, parece cumprir simultaneamente duas funções no jogo: por uma parte, interpreta o papel; e, por outra, verifica o seu comportamento. A conduta arbitrada não se caracteriza apenas pela presença de um modelo, mas também pela comprovação da imitação do modelo (p. 420).

Sendo o conteúdo dos papéis, representados pelas crianças, as normas de relações entre as pessoas, ou seja, as normas de conduta social, entendidas como fonte do desenvolvimento moral da criança, a brincadeira de faz de conta de papéis sociais possibilita a elas passar "a um mundo desenvolvido de formas supremas de atividade humana, a um mundo desenvolvido de regras e relações entre as pessoas" (ELKONIN, 2009, p. 420).

Portanto, como exemplifica o episódio e de acordo com Elkonin (2009, p. 421), uma coletividade infantil bem ajustada pode inculcar independência, educar no amor ao trabalho, corrigir alguns desvios comportamentais, desenvolver a colaboração e a autoconsciência. Esses 
efeitos educativos desenvolvidos na brincadeira exercem influência sobre o desenvolvimento psíquico da criança e sobre a formação de sua personalidade.

Todas essas ressignificações são exemplos de conteúdo das relações sociais historicamente estabelecidas. E, dialeticamente, são repercutidos modelos positivos e negativos das formas de interação entre as pessoas nas brincadeiras das crianças, cabendo à educação criar condições para que elas internalizem o que for positivo ao desenvolvimento de sua personalidade, de modo a, também, refletirem e contraporem-se às mazelas sociais.

\section{Considerações finais}

Sintetiza-se e complementa-se, a seguir, as ideias produzidas ao longo das análises dos dados, a fim de possibilitar uma melhor compreensão do tema tratado.

As brincadeiras de papéis sociais de argumento do trabalho (atividade guia do desenvolvimento da pessoa adulta) deixaram evidentes a competitividade, o lucro, provenientes da relação capitalista e, contraditoriamente, mostraram-se como possibilidades de desenvolvimento da cooperação, do cuidado, da atenção para com o outro, da autoafirmação e da empatia entre as crianças brincantes.

Os episódios da pesquisa revelaram processos psicológicos em níveis reais e iminentes de desenvolvimento nas crianças, como a imaginação, a memória, o controle da vontade, a fala, a função simbólica da consciência e a escrita. Essas qualidades humanas têm uma complexa relação com o desenvolvimento da personalidade infantil, pois fazem parte das construções históricas da humanidade e estão presentes nas relações sociais. O não desenvolvimento delas pode implicar negativamente no desenvolvimento da personalidade infantil, que tem como base as relações sociais, pois desenvolver as funções psíquicas superiores significa ter o domínio dos procedimentos e modos culturais da conduta humana e desenvolver-se de forma integral, o que inclui a personalidade, significa dominar formas especiais de comportamento originadas ao longo do processo de desenvolvimento histórico da humanidade.

Dessa forma, quando Vigotski (1995/2000, p. 45 - traduziu-se) afirma que "a história do desenvolvimento cultural da criança nos conduz à história do desenvolvimento da personalidade", ele explica que as possibilidades que a criança tem de internalizar a cultura (funções psíquicas, ferramentas e signos sociais) influi diretamente no modo como elas se relacionarão com o mundo, com os outros e na consciência que desenvolverão sobre si mesmas.

Espera-se que esta pesquisa possa engrenar novos estudos acerca da brincadeira de faz de conta de papéis sociais, em busca da valorização e do reconhecimento dessa atividade como 
norteadora do desenvolvimento infantil, frente aos modelos de ensino mecanicistas, controladores e redutores da imaginação, da criação e da liberdade. A brincadeira de faz de conta, em sua liberdade ilusória, permite a expressão do que a criança tem internalizado das relações sociais, por isso, é uma atividade imprescindível no contexto escolar, na educação da personalidade humana.

\section{Referências}

ELKONIN, Daniil B. Psicologia do jogo. Tradução: Álvaro Cabral. 2. ed. São Paulo: WMF Martins Fontes, 2009.

KISHIMOTO, Tizuko Morchida. Jogo, brinquedo, brincadeira e a Educação. São Paulo: Cortez, 2000.

MARCOLINO, Suzana. Brincadeiras de papéis na escola da infância. In: COSTA, Sinara Almeida da; MELLO, Suely Amaral (orgs.). Teoria histórico-cultural na educação infantil: conversando com professoras e professores. 1. ed. Curitiba, PR: CRV, 2017.

MUKHINA, Valéria. Psicologia da idade pré-escolar. Tradução: Claudia Berliner. São Paulo: Martins Fontes, 1995.

VIGOTSKI, Lev. S. A brincadeira e o seu papel social no desenvolvimento psíquico da criança. Tradução: Zoia Prestes. Rio de Janeiro: Revista Virtual de Gestão de Iniciativas Sociais, $\mathrm{n}^{\circ}$ 11, julho de 2008, Disponível em:

https://isabeladominici.files.wordpress.com/2014/07/revista-educ-infant-indic-zoia.pdf . Acesso em 15 mar.2021.

VIGOTSKI, Lev. S. El problema del desarrollo de las funciones psíquicas superiores. In: VIGOTSKI, Lev. S. Obras escogidas - Tomo III. Madrid: Visor DIS., S. A, 1995/2000. p. 1146.

VIGOTSKI, Lev. S. Imaginação e criação na infância. Ensaio psicológico: livro para professores. Tradução Zoia Prestes. São Paulo: Ática, 2009.

VIGOTSKI, Lev. S. Método de investigacion. In: VIGOTSKI, Lev. S. Obras escogidas Tomo III. Madrid: Visor DIS., S. A, 1995/2000a. p. 47-96.

VIGOTSKI, Lev. S. Psicologia pedagógica. Tradução: Paulo Bezerra. $3^{\text {a }}$ ed. São Paulo, SP: WMF Martins Fontes, 2010.

VIGOTSKI, Lev. S. Quarta aula: a questão do meio na pedologia. Tradução: Márcia Pileggi Vinha. Psicologia USP, São Paulo, 2010a, 21 (4), p. 681-701. 